\title{
Linking climate variability to mushroom productivity and phenology
}

\author{
Ulf Büntgen ${ }^{1,2 *}$, Håvard Kauserud ${ }^{3}$, and Simon Egli ${ }^{1}$
}

Climate change affects ecological systems across various spatiotemporal scales and disrupts the life cycles of resident organisms. Little is known about the environmental drivers of mushroom productivity and phenology, partially because the life cycle of fungi is mostly belowground. Here, we present results from a field survey, in which a total of 65631 unique individual mycorrhizal mushrooms - representing 273 species - were recorded during weekly intervals from 1975 to 2006 in a nature reserve in Switzerland. The average annual number of observed mushrooms increased from 1313 (pre-1991) to 2730 (1991 and thereafter), while average fruiting time during the latter period was delayed by 10 days as compared with that of the former. Precipitation amounts and temperature means determined fungal activity. Reconstructed intra-annual timing of mushroom fruiting for the 20th century paralleled contemporary Swiss wine harvest dates, providing independent evidence of climateinduced ecosystem change. Enhanced growth conditions and extended growing seasons appear beneficial to fungi from both a socioeconomic and an ecological perspective, because most vascular plants interact with mycorrhizal fungi to generate biomass.

Front Ecol Environ 2012; 10(1): 14-19, doi:10.1890/110064 (published online 1 Jul 2011)

$\mathrm{E}$ cological responses to climate variations have been reported for a broad range of taxa, including fungi (Gange et al. 2007; Kauserud et al. 2008, 2010), across a variety of spatiotemporal scales (Menzel and Fabian 1999; Stenseth et al. 2002). Interannual fluctuations and longer-term trends in the formation of fungal fruiting bodies (mushrooms), as well as intra-annual shifts in the timing of their productivity, have been related to landuse/land-cover changes (including deforestation), increased harvesting, and pollution (Hall et al. 2003; Gillet et al. 2010), among other factors. A causal explanation of spatiotemporal variations in mushroom harvest, however, is still absent because of unsystematic, incomplete fungal monitoring efforts and/or inventories of insufficient duration or resolution (WebTable 1). A lack of complete and continuous recording series therefore confounds any meaningful comparison with external factors, including climate variations. Understanding past, present, and projected variations in mushroom harvest and their association with a changing climate, however, appears to be relevant not only from an ecological point of view but also from an economic perspective, given that some edible mycorrhizal fungi are among the world's most expensive delicacies (Hall et al. 2003).

Ectomycorrhizal (ECM) fungi spend most of their life cycle in the belowground microbial stage, where they live in close association with the fine root systems of their respective host plants (Smith and Read 1997). The

\footnotetext{
${ }^{1}$ Swiss Federal Research Institute for Forest, Snow and Landscape, Birmensdorf, Switzerland (buentgen@wsl.ch); ${ }^{2}$ Oeschger Centre for Climate Change Research, Bern, Switzerland; ${ }^{3}$ Microbial Evolution Research Group, Department of Biology, University of Oslo, Oslo, Norway
}

mycelia (mass of thread-like hyphae that form the vegetative part of the fungus) of ECM fungi increase the efficiency of water and nutrient absorption in host plants (eg trees), thereby enhancing their resistance to pathogens (Smith and Read 1997). Photosynthetic products are, in return, delivered by the host plants to the fungal partners, enabling mycelial formation and mushroom production, which represent an important food supply for many soil invertebrates and small mammals (Krebs et al. 2008). Soil characteristics, in tandem with the host plant's carbohydrate allocation, may also influence the amount (production) and timing (phenology) of ECM fruiting bodies (Straatsma et al. 2001; Egli et al. 2010; Gillet et al. 2010; Pinna et al. 2010). Almost all vascular plants interact with mycorrhizal fungi in the rhizosphere. This symbiotic relationship has considerable impact on carbon dioxide $\left(\mathrm{CO}_{2}\right)$ sequestration in terrestrial ecosystems (Högberg and Read 2006; Orwin et al. 2011) by increasing the amount of biomass turnover and carbon (C) exchange.

Here, we present data from a field survey, in which 65631 discrete mushrooms were systematically registered on a weekly basis between 1975 and 2006 in a Swiss nature reserve. The number of emerging mycorrhizal mushrooms and their annual fruiting time are then compared with European climate indices, as well as with reconstructed Swiss wine harvest dates.

\section{Methods}

\section{Study site and sampling design}

Mushroom monitoring was performed each week (without interruption during fruiting season) over a 36-year period in the 75-ha fungus reserve known as La Chanéaz, in western Switzerland ( $\sim 585 \mathrm{~m}$ above sea level; $46^{\circ} 47^{\prime} 55^{\prime \prime}$ to 
$46^{\circ} 48^{\prime} 10^{\prime \prime} \mathrm{N}, 6^{\circ} 59^{\prime} 52^{\prime \prime}$ to $7^{\circ} 00^{\prime} 30^{\prime \prime} \mathrm{E}$; Figure 1). The protected area consists of a multistoried, mixed-beech forest growing on Calcaric Cambisol soils. The dominant tree species is beech (Fagus sylvatica); these individuals are about 28-44 $\mathrm{m}$ in height. A traditional, so-called "femel system" of forest management - periodic, small-area interventions to correct for stand-closing tendencies and to ensure natural regeneration by native tree species in the reserve was applied before and during the 1975-2006 monitoring period at La Chanéaz. Two-meter-high fences installed along the border of the $1500-\mathrm{m}^{2}$ study area prevented interference by mushroom pickers and forest animals.

All epigeous (aboveground) fruiting bodies of larger fungi within five $300-\mathrm{m}^{2}$ plots were macroscopically and/or microscopically identified, counted, and mapped at weekly intervals. Systematic and continuous observations covered the calendar weeks $18-52$ that correspond to the mushroom fruiting season and spanned the 1975-2006 monitoring period. Identified fruiting bodies were marked with methylene blue stain to avoid repeat counts. Non-edible fungal species were not recorded between 1980 and 1983. Our study concentrated on mycorrhizal species, because both their productivity and phenology are likely to reflect environmental signals more strongly and because they are less prone to sporadic disturbance. Hypogeous (belowground) mushrooms were not considered, given that their systematic excavation would have had destructive physical effects within the reserve and thus counteracted any long-term monitoring.

\section{Data assessment and comparison}

Accumulated weekly fruiting body counts (WFBC) and their cumulative sums were computed over the full monitoring period (1975-2006) and also at three intervals within the study (1975-1990/1983-1998/1991-2006); these were used to assess intra-annual dynamics and were associated with additional significance tests. The sum of the products of calendar weeks and their corresponding counts divided by the total annual fruiting body counts the weighted week of appearance (hereafter WWA) refers to intra-annual mushroom peaks. Seasonal totals of counts and their timing quantified temporal changes in interannual mushroom productivity and phenology. Firstorder autocorrelation coefficients of the weekly fruiting body counts, calculated for each year, were used to detect structural response changes in mushroom productivity. We calculated the intra-annual temporal autocorrelation structure from the WFBC independently for each year between 1975 and 2006.

Gridded $\left(0.5^{\circ} \times 0.5^{\circ}\right)$ indices of monthly temperature (minimum, mean, and maximum), diurnal temperature range, precipitation totals, soil moisture availability, and cloud cover fraction were developed with data from the CRUTS3 database and used for spatial field correlation analysis over the North Atlantic/European sector $\left(30^{\circ} \mathrm{N}-70^{\circ} \mathrm{N}\right.$ and $\left.10^{\circ} \mathrm{W}-40^{\circ} \mathrm{E}\right)$. Soil moisture availability is expressed as the integral of temperature means, precipitation totals, and soil characteristics, in the form of a drought metric known as the self-calibrated Palmer Drought Severity Index (scPDSI). Seasonal mushroom means and their time of emergence were correlated against monthly and seasonal means of different climate indices (as introduced above), over different temporal intervals.

Intra- and interannual variations in regional-scale $\left(46-46.5^{\circ} \mathrm{N}\right.$ and $\left.6.5-7^{\circ} \mathrm{E}\right)$ climate were evaluated. Mean and variance of regional August temperature (maxima) data were scaled to the emergence data from 1975-2006, for reconstruction purposes. Calibration statistics regarding possible trends between the actual and estimated values - so-called Durbin-Watson indices (DW; Durbin and Watson 1951) - as well as the root mean squared error (RMSE) were computed. A temperature reconstruction based on Swiss wine harvest dates (Meier et al. 2007) was used for comparison, 


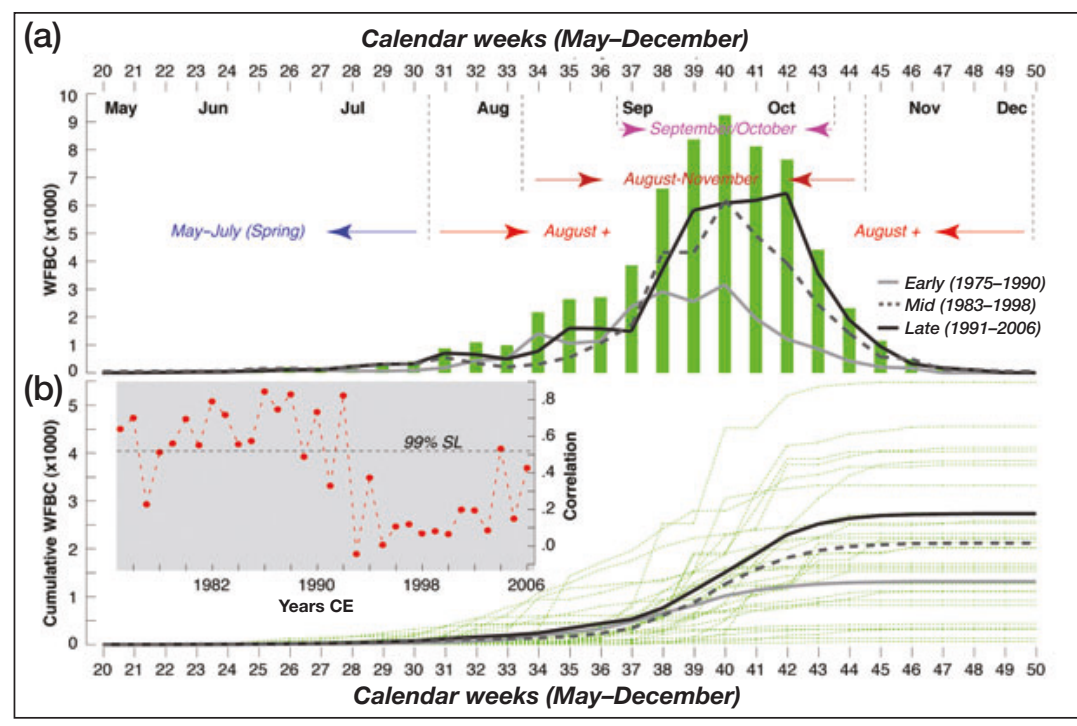

Figure 2. (a) Weekly fruiting body counts (WFBC) between 1975 and 2006 (green bars) and averages of three early/mid/late (1975-1990/1983-1998/ 1991-2006) periods (lines). (b) The cumulative sum of WFBC shown for each year between 1975 and 2006; the light, dashed, and dark lines refer to their early/mid/late period means, respectively. First-order autocorrelation structure of the WFBC shown for each year between 1975 and 2006 (inset). The 99\% significance level (SL) was corrected for the mean first-order autocorrelation of 0.43 .

and cubic smoothing splines were calculated for timeseries filtering.

\section{Results and discussion}

Two hundred seventy-three different ECM fungal species were included in the inventory, with an average mushroom count of 240 per species. The mean weekly total was 65 mushrooms, with a maximum count of 1987 mushrooms in week 40 (October 1993). All counts conducted from 1975 to 2006 indicated a continuous intraannual production increase from late June until early October (Figure 2a), followed by decreasing numbers of mushrooms until December (WebTable 2).

A split-period approach to intra-annual inventory analysis reveals a significant ( $t$ test, $P=0.003$ ) increase in mushroom harvest from the first to the second half of the inventory period (Figure 2a; WebTable 3). Independently averaged over the "early" (1975-1990) and "late" (1991-2006) intervals, the WFBC increased from 42 to 88, with standard deviations (SD) increasing from 100 to 240. The cumulative sum of weekly mushroom numbers (Figure $2 \mathrm{~b})$ shows that the seasonal window of peak mushroom production was between late August and October, and further highlights the increase in mushroom counts that occurred between 1975 and 1990 and between 1991 and 2006.

This boost in fungal harvest may be explained by improved growth conditions, not only for the ECM fungi but also for the host plants, as a result of recent climate change. Increasing central European temperatures during the second half of the 20th century and an associated extension of the growing season (Menzel and Fabian 1999) may have resulted in greater availability of photosynthetic products to the fungal symbionts over longer periods, enabling higher productivity of fruiting bodies. However, this increase in the number of mushrooms contradicts previously reported, large-scale disappearances of fruiting bodies (Gange et al. 2007), with declining numbers of the Périgord black truffle (Tuber melanosporum) in southern Europe and the matsutake (Tricholoma matsutake) in eastern Asia being the most prominent examples (Hall et al. 2003). These contradictory findings may reflect regional differences in ecological responses to climate fluctuations (Stenseth et al. 2002; Büntgen et al. 2010). Warmer and drier habitats, such as those associated with Mediterranean truffle foci, may already be experiencing drought-induced reductions in mycelial growth, whereas temperate central European biomes may still be benefiting from a warmer climate (Büntgen et al. 2011). In either case, the current lack of knowledge about the external drivers of hypogeous fungal productivity and phenology calls for more research (Bertault et al. 1998; Martin et al. 2010; Trappe and Claridge 2010).

Notably, no major site-specific alterations in forest species composition and structure occurred either before or during the study period, making this an unlikely explanation for the observed changes. The presence of the protective fence surrounding the site had no obvious impact on fungal fruiting, because the relationship between mushroom harvesting and mushroom production was statistically non-significant (Egli et al. 2006). Increased levels of nitrogen deposition during the study period would be expected to have the opposite effect on productivity of ECM fungi (Gillet et al. 2010) relative to what we observed. We would argue, therefore, that large-scale climate variations during the 20th century are the most likely factors driving the observed changes in mushroom productivity and phenology.

The increase in Swiss mushroom harvest coincides with an average delay in peak fruiting time of 10 days (Figure 2; WebFigure 1). The average time of fruiting shifted from week 38.2 (during the period 1975-1990) to week 39.4 (during 1991-2006), while the earliest and latest average fruiting dates occurred in week 34.7 in 1977 and in week 41.8 in 1998, respectively (WebTable 2). Our results match previously described delays in intra-annual fungal fruiting in other regions of the boreal, temperate, and semiarid forest zones (Munguia et al. 2006; Kauserud et al. 2008). An extended growing season (Menzel and Fabian 1999) may have enhanced delayed fruiting. An abrupt shift in the temporal autocorrelative structure of weekly mushroom counts - from significant positive coefficients to non-significant coefficients - occurred in the 


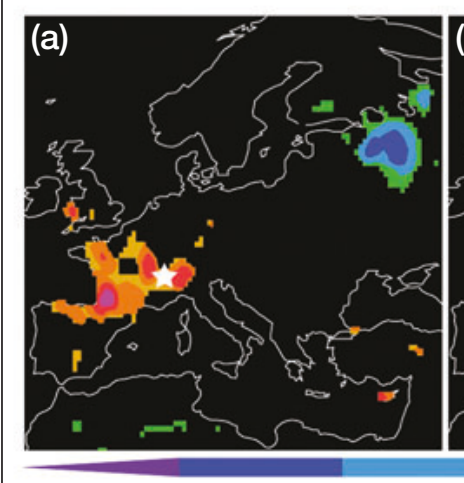

$-0.6$

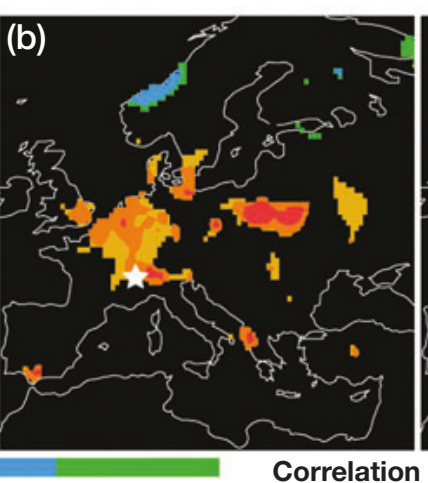

$-0.4$

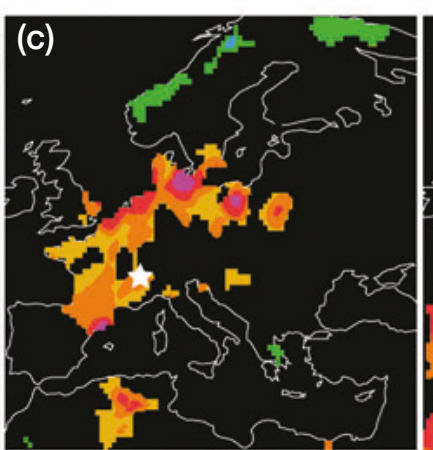

0.3

0.4

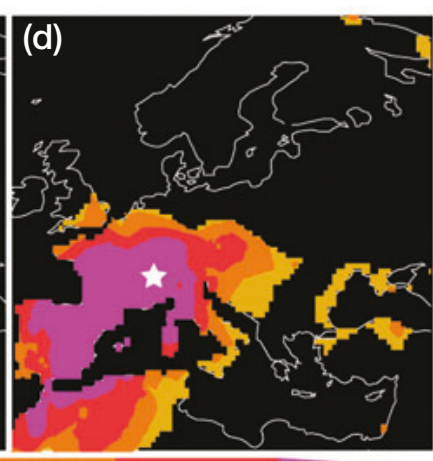

0.5
0.6

Figure 3. Spatial field correlations of (a) spring (June-July), (b) summer (August-September), and (c) autumn (October-November) weekly fruiting body counts (WFBC) against June, August, and September precipitation totals, respectively. (d) Spatial field correlations of the weighted week of appearance (WWA) against August maximum temperature. Correlations are computed over the 1975-2006 period, and the white star indicates the location of the study site.

early 1990s (Figure 2, inset). We speculate that the trigger for mycorrhizal mushroom formation may have shifted from an annual energy accumulation threshold to more immediate responses to environmental conditions. Fungal mycelia may require a certain period of time to accumulate fruiting potential (Krebs et al. 2008); with increased energy acquisition from the host, the mandatory time to acquire fruiting potential will decrease, enabling a more direct response to optimal conditions after about the early 1990s.

Continental-wide correlation maps for Europe depict significant positive relationships between spring, summer, and autumn mushroom abundance and the precipitation totals of the three seasonal periods: June-July, August-September, and October-November (Figure 3, $\mathrm{a}-\mathrm{c})$. The location of the study site is included in the geographical range of significant positive correlations for all three seasons. The spatial correspondence between precipitation and fruit body production extends into southwest Switzerland and further expands northwestwardly into Scandinavia, and toward Iberia in the southwest by the end of the growing season (October-November). This response pattern reflects the spatial heterogeneity of precipitation distribution. As compared to correlations with mushroom harvests, correlations between the average fruiting time and August temperature maxima were less patchy and generally higher. The spatial extent of high correspondence $(r>0.6)$ between temperature and fruiting time covers most of southwestern Europe and large parts of northwestern Africa (Figure 3d). The observed increase and simultaneous shift in mushroom emergence corresponds to warmer and wetter summers during the late 20th century (WebFigures 2 and 3). The utilization of more complex and integrative climate parameters - such as diurnal temperature range, soil moisture availability, and cloud cover - revealed generally non-significant and temporally unstable correlations with any of the various mushroom time-series (WebFigures 4 and 5). These unexpected results may suggest direct rather than indirect climate con- trols on both mushroom productivity and phenology.

Correlation between the annual average fruiting time and regional-scale August maximum temperature increased from 0.74 back to 1975 to 0.92 after the timeseries are smoothed with a 10-year low-pass filter. This strong relationship allows the annual average fruiting time to be reconstructed over the 20th century (Figure 4a). Both the estimated and actual fruiting time tended to be early in the season during the exceptionally wet and cold period between 1977 and 1979 (WebFigure 2), whereas a relatively late fruiting time corresponded to the dry and hot summers of 1989 through 1992. Late annual fruiting is estimated for the 1940s. Early average fruiting dates have been observed during the 1910s, 1920s, and 1960s.

Because grape growth and ripening across the Swiss Plateau are closely linked to variations in April-August temperatures and also relate to the harvest date at the end of the growing season, wine harvesting dates were used as a climate proxy (Meier et al. 2007). Our new reconstruction of mushroom fruiting time and the Swiss temperature reconstruction based on grape harvest dates share common decadal-scale variability during the 20th century (Figure $4 \mathrm{~b}$ ). The pronounced correspondence between the reconstructed annual fruiting dates and country-wide grape harvest dates is evidence that our mushroom inventory from a single forest plot is representative of patterns over a broader geographical scale. Indeed, about $50 \%$ of the total forested area in Switzerland consists of similar beech forests, with the same ratio also occurring throughout central Europe (Wohlgemuth et al. 2008).

Our results may have implications beyond the dynamics of regional forest growth, including effects on the large-scale C cycle (Orwin et al. 2011), because fungal mycelia contribute substantially to the organic soil fraction and further affect $\mathrm{CO}_{2}$ exchange rates with the atmosphere (Högberg and Read 2006). ECM fungi are therefore important players in the global $\mathrm{C}$ cycle, given that up to $30 \%$ of the forest net primary production is 


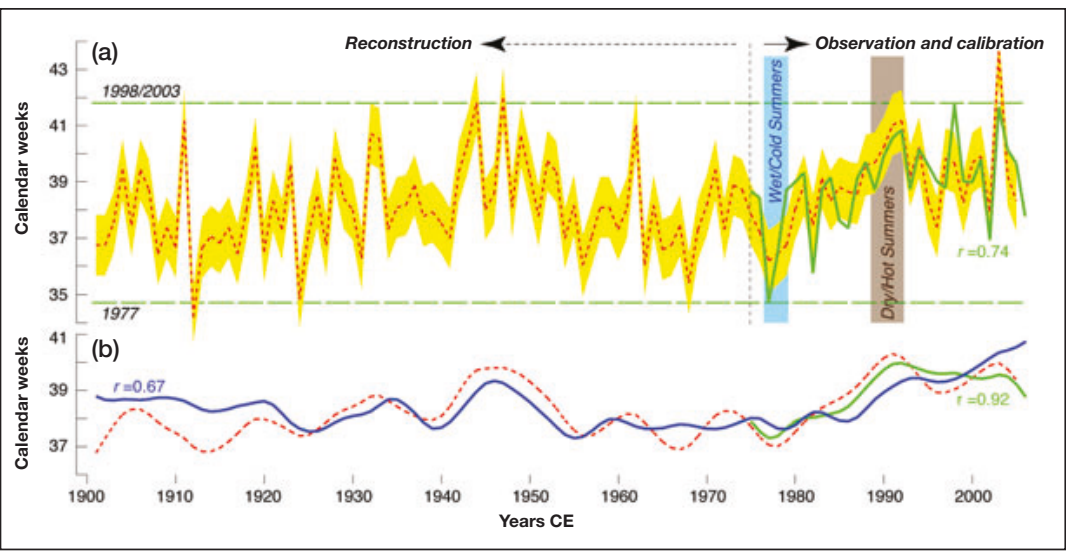

Figure 4. (a) Observed (green) and reconstructed (red) weighted week of appearance (WWA) with scaled (1975-2005) August temperature maxima back to $1901 \mathrm{CE}$. The yellow shading represents the RMSE $( \pm 1)$ of the calibration period. No trend $(0.0)$ occurs in the model residuals $(D W=1.83)$. The horizontal dashed lines indicate the calibration amplitude obtained from the observed WWA (green). (b) Comparison of the reconstructed WWA (red) with (inverse) grape harvest dates from Switzerland (blue) after scaling and smoothing with a 10-year low-pass filter.

allocated - through the tree-root interface - to its symbiotic partners. Soil respiration almost balances $\mathrm{C}$ fixation by terrestrial photosynthesis and exceeds all anthropogenic $\mathrm{C}$ emissions by one order of magnitude. Half of this soil respiratory $\mathrm{C}$ release derives from living plant roots and their mycorrhizal fungal partners (Högberg and Read 2006; Orwin et al. 2011). Therefore, as major agents of $\mathrm{C}$ cycling in forests, mycorrhizal fungi play a critical role in forest ecosystem sustainability and $\mathrm{C}$ sequestration.

Previously published mushroom inventories with continuous successive recording lengths of up to 16 years (Shaw et al. 2003) mirror the patterns that we observed (WebTable 1). Progressive effects of stand aging (Martinez de Aragon et al. 2007) are negligible, whereas the timing of precipitation totals drives fungal fruiting (Eveling et al. 1990; Martinez de Aragon et al. 2007; Krebs et al. 2008; Bonet et al. 2010) and soil moisture availability becomes particularly important in semiarid ecosystems (Ogaya and Penuelas 2005; Barroetavena et al. 2008). Summer temperatures have been found to affect mushroom phenology under more humid conditions (Munguia et al. 2006; Pinna et al. 2010). We provide another independent line of evidence for climate-induced changes in ecosystem activity and underline the importance of high-resolution ecological monitoring over extended periods. We believe that our unique archive may also allow validation - and perhaps even calibration - of more heterogeneous data from herbaria (Kauserud et al. 2008, 2010) that are characterized by unsystematic and sporadic entries.

\section{Conclusions}

A careful analysis of the longest fungal inventory has provided evidence for an approximate doubling in the number of mushrooms, from an annual mean of fruiting body counts from 1313 (before 1991) to 2730 (afterwards). This substantial boost in productivity coincided with a 10 -day delay in average fruiting time. The observed changes can be explained by improved growth conditions and extended growing seasons during the late 20th century, not only for the fungi but also for their host plants. Seasonal mushroom yields show a significant positive correlation with regional precipitation totals, while the annual timing of mushroom fruiting is directly associated with August temperature maxima. Reconstructed intra-annual timing of mushroom fruiting paralleled Swiss wine harvest dates back to 1900 CE. Our results provide independent evidence for climate-induced, long-term ecosystem change at broader spatial scales. We hypothesize that enhanced growth conditions and extended growing seasons appear beneficial from an economic as well as from an environmental perspective. An increase in the number of fungal fruiting bodies represents an edible attraction for both humans and animals, affects the organic soil fraction, supports forest health, enhances biodiversity, increases terrestrial biomass turnover, and may even influence the global $\mathrm{C}$ cycle.

\section{Acknowledgements}

We thank F Ayer for mycological field and herbarium work; DM Johnson, DC Frank, JF Gonzalez-Rouco, and NC Stenseth for discussion; and the Swiss National Science Foundation (National Centre of Competence in Research) and the EU project Millennium (017008) for funding. This study benefited from the January 2011 workshop on mushroom phenology held at the Centre for Ecological and Evolutionary Synthesis (University of Oslo, Norway), and was written during a (Santander) Guest-Professorship for UB at the University of Madrid, Department of Astrophysics.

\section{References}

Barroetavena C, La Manna L, and Alonso MV. 2008. Variables affecting Suillus luteus fructification in ponderosa pine plantations in Patagonia (Argentina). Forest Ecol Manag 256: 1868-74.

Bertault G, Raymond M, Berthomieu A, et al. 1998. Trifling variation in truffles. Nature 394: 734.

Bonet JA, Plahí M, Colinas C, et al. 2010. Modelling the production and species richness of wild mushrooms in pine forests of the Central Pyrenees in northeastern Spain. Can J Forest Res 40: 347-56.

Büntgen U, Franke J, Frank D, et al. 2010. Assessing the spatial signature of European climate reconstructions. Clim Res 41: 125-30.

Büntgen U, Tegel W, Egli S, et al. 2011. Truffles and climate change. Front Ecol Environ 9: 150-51.

Durbin J and Watson GS. 1951. Testing for serial correlation in least squares regression. Biometrika 38: 159-78. 
Egli S, Peter M, Buser C, et al. 2006. Mushroom picking does not impair future harvest - results of a long-term study in Switzerland. Biol Conserv 129: 271-76.

Egli S, Ayer F, Peter M, et al. 2010. Is forest mushroom productivity driven by tree growth? Results from a thinning experiment. Ann Forest Sci 67: 509.

Eveling DW, Wilson RN, Gillespie ES, and Bataille A. 1990. Environmental effects of fruit body counts over fourteen years in a forest area. Mycol Res 94: 998-1002.

Gange AC, Gange EG, Sparks TH, and Boddy L. 2007. Rapid and recent changes in fungal fruiting patterns. Science 316: 71.

Gillet F, Peter M, Ayer F, et al. 2010. Long-term dynamics of aboveground fungal communities in a subalpine Norway spruce forest under elevated nitrogen input. Oecologia 164: 499-510.

Hall IR, Wang Y, and Amicucci A. 2003. Cultivation of edible ectomycorrhizal mushrooms. Trends Biotechnol 21: 433-38.

Högberg P and Read DJ. 2006. Towards a more plant physiological perspective on soil ecology. Trends Ecol Evol 21: 548-54.

Kauserud H, Stige CL, Vik JO, et al. 2008. Mushroom fruiting and climate change. P Natl Acad Sci USA 105: 3811-14.

Kauserud H, Heegaard E, Semenov MA, et al. 2010. Climate change and spring-fruiting fungi. P Roy Soc B-Biol Sci 277: 1169-77.

Krebs CJ, Carrier P, Boutin S, et al. 2008. Mushroom crops in relation to weather in southwestern Yukon. Botany 86: 1497-502.

Martin F, Kohler A, Murat C, et al. 2010. Périgord black truffle genome uncovers evolutionary origins and mechanisms of symbiosis. Nature 464: 1033-38.

Martinez de Aragon J, Bonet JA, Fischer CR, and Colinas C. 2007. Productivity of ectomycorrhizal and selected edible saprotrophic fungi in pine forests of the pre-Pyrenees mountains, Spain: predictive equations for forest management of mycological resources. Forest Ecol Manag 252: 239-56.

Meier N, Rutishauser T, Pfister C, et al. 2007. Grape harvest dates as a proxy for Swiss April to August temperature reconstructions back to AD 1480. Geophys Res Lett 34: L20705; doi:10.1029/2007GL031381.

Menzel A and Fabian P. 1999. Growing season extended in Europe. Nature 397: 659

Munguia P, Guzman G, and Ramirez-Guillen F. 2006. Seasonal community structure of macromycetes in Veracruz, Mexico. Ecography 29: 57-65.

Ogaya R and Peñuelas J. 2005. Decreased mushroom production in a Holm oak forest in response to an experimental drought. Forestry 78: 279-83.

Orwin KH, Kirschbaum MUF, St John MG, and Dickie IA. 2011. Organic nutrient uptake by mycorrhizal fungi enhances ecosystem carbon storage: a model-based assessment. Ecol Lett 14: 493-502.

Pinna S, Gévry MF, Côté M, and Sirois L. 2010. Factors influencing fructification phenology of edible mushrooms in a boreal mixed forest of Eastern Canada. Forest Ecol Manag 260: 294-301.

Shaw PJA, Kibby G, and Mayes J. 2003. Effects of thinning treatment on an ectomycorrhizal succession under Scots pine. Mycol Res 107: 317-28.

Smith SE and Read DJ. 1997. Mycorrhizal symbiosis, 2nd edn. London, UK: Academic Press.

Stenseth NC, Mysterud A, Ottersen G, et al. 2002. Ecological effects of climate fluctuations. Science 297: 1292-96.

Straatsma G, Ayer F, and Egli S. 2001. Species richness, abundance, and phenology of fungal fruit bodies over 21 years in a Swiss forest plot. Mycol Res 105: 515-23.

Trappe J and Claridge AW. 2010. The hidden life of truffles. Sci Am 302: 78-84.

Wohlgemuth T, Moser B, Brändli UB, et al. 2008. Diversity of forest plant species at the community and landscape scales in Switzerland. Plant Biosyst 142: 604-13.

\section{Evolutionary Ecologist}

The Department of Biology of Susquehanna University invites applications for a tenure-track position at the rank of Assistant Professor in an area of evolutionary ecology, beginning Fall 2012. Demonstrated success or evidence of potential for excellence in teaching and advising undergraduates is essential. Teaching duties include introductory-level biology for majors, non-majors science courses, and courses in area of specialization in the biology and ecology majors. An active research program is required, with a commitment to fostering undergraduate student involvement. Ph.D. required.

Review of applications begins February 1, 2012, and will continue until the position is filled.

Applications should include a letter of application, curriculum vitae, transcripts, statement of teaching objectives and research interests, three letters of reference, and a current email address.

Application materials should be sent electronically to Dr. Thomas Peeler, Chair, at

\section{biology@susqu.edu}

\section{If submitted by U.S. Postal Service, send to Dr. Thomas Peeler, Department of Biology, Susquehanna University, 514 University Avenue, Selinsgrove, PA 17870.}

Founded in 1858, Susquehanna University is a selective, residential, national liberal arts college that prepares undergraduate students for achievement, leadership, and service in a diverse, interconnected world. Academic excellence, study away and service learning, student-faculty collaboration, and rich opportunities for creative and personal growth are hallmarks of a Susquehanna University education. More than 2,200 students come to Susquehanna from 36 states and 13 countries, and more than 90 percent of them find jobs or pursue graduate study within six months of graduation. The university is located in central Pennsylvania, in the town of Selinsgrove, along the banks of the scenic Susquehanna River and about three hours from major East Coast cultural, financial, and recreational centers. For more information, visit www.susqu.edu. Susquehanna University is committed to creating a more diverse community.

The university encourages candidates from historically underrepresented groups to apply.

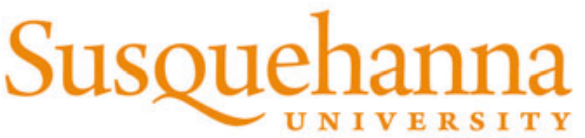

Susquehanna is an EO/AA employer. 